\title{
Clinical Manifestations and Treatment of Caries from 1953 to Global Changes in the 20th Century
}

\author{
K.G. König \\ Department of Preventive and Community Dentistry and Pedodontology, University Medical Center St. Radboud, \\ Nijmegen, The Netherlands
}

\author{
Key Words \\ Caries manifestations · Caries treatment $\cdot$ Caries risk · \\ Caries prevention
}

\begin{abstract}
Manifestations and treatment of caries are strongly dependent on caries risk and the severity of the attacking factors which determine the degree of caries activity. Caries activity in turn will be modified and can be minimized by effective preventive measures. Exemplary cases and events will be discussed to illustrate what has happened since the establishment of ORCA 50 years ago.
\end{abstract}

Copyright $@ 2004$ S. Karger AG, Basel

\section{Relation of Caries Manifestations and Treatment to Caries Risk and Prevention}

The clinical manifestations of caries and the principles of caries treatment are closely interrelated, and both depend on caries risk and caries activity.

In 1953, at the University of Würzburg, caries treatment was still being taught according to the principles laid down by G.V. Black [1914]. Hand instruments were used especially for opening a cavity, and for 'extension for prevention' according to the risk of future (secondary) manifestations of caries. The less clean a mouth was, the larger the box of a cavity had to be both buccally and lingually [Black, 1899; Hofheinz, 1902]. Cavity preparation according to the local microenvironment was one of Black's important treatment principles. It illustrates the fact that treatment must be guided not only by the manifestations of caries, but also by the assessment of the individual's caries risk. As we well know, this risk depends on the preventive agents and services which are available to the individual and the extent to which these are used effectively by the patient.

After World War II, in both West and East, the reindustrialization of a starving Europe and the boom which followed led to an overconsumption of sweets and many other types of luxury food. Tito's Yugoslavia spent nearly all its Western hard currencies to buy wheat from the West, simply because Tito's people associated white bread with progress, and it was necessary to demonstrate that in a modern socialist country progress was actually taking place.

In particular, sugar consumption in many countries almost reached a level of $1 \mathrm{~kg}$ per person per week, and this combined with the lack of good oral hygiene resulted in a tremendous rise in the incidence of caries. Adequate

\section{KARGER}

Fax +4161306 1234

E-Mail karger@karger.ch

www.karger.com
(C) 2004 S. Karger AG, Basel

0008-6568/04/0383-0168\$21.00/0

Accessible online at:

www. karger.com/cre
Prof. Dr. K.G. König

Weezenhof 2906

NL-6536 HM Nijmegen (The Netherlands)

Tel. +31243449624, Fax +31243442019

E-Mail k.konig@mailbox.kun.nl 
individual dental care became nearly impossible, not least, for instance, in the juvenile populations of Switzerland. In its mountainous areas dentitions were so bad that a most welcome wedding gift was not the usual dowry, but payment for the extraction of all teeth, with the subsequent provision of full dentures. This radical approach solved two problems once and for all: firstly, there would be no recurrent problem of toothache occurring in midwinter in a high mountain valley, and, secondly, the elimination of a potential financial burden on young husbands, in the form of recurring high dentist's bills. The same sort of 'caries treatment', that is full clearance, was also practiced and well documented in Scotland between 1967 and 1972.The numbers of teeth sacrificed especially in people with no previous denture experience are shocking. In 52\% of the subjects 21 or more teeth were extracted and full dentures fitted. Many patients were less than 30 years old when a full clearance was performed [Todd and Whitworth, 1974; Marthaler, 2002].

Obviously in post-war Europe there was not only the problem of individual dental care, but a public health problem plaguing entire populations from birth to death. That was the desperate state of dental conditions when the ORCA was founded in 1953. While the dental professions found exodontism unacceptable, the shortage of dentists could not be alleviated instantly - so disease prevention needed to be practiced on the largest scale possible.

\section{Influence of Prevention versus Non-Prevention on Caries Manifestations and Treatment}

The topic of this paper is the manifestations and treatment of caries, and not prevention and its history over the past 50 years. It is, nonetheless, essential to direct attention to prevention because effective preventive measures have clearly influenced manifestations of caries and, secondarily, treatment principles. The preventive effect of fluoride on caries had been unequivocally established by Trendley Dean and his co-pioneers [Dean et al., 1942]. By 1953, even in Europe there was no doubt that this was the key to preventing caries.

The original name of ORCA chosen in 1953 was 'Organisme Européen de Coordination des Recherches sur le Fluor et la Prophylaxie de la Carie Dentaire' or 'European Association for the Coordination of Research on Fluoride and Prevention of Dental Caries'. This was logical both as a name and as a programme. North American investigators had shown that fluoride (in drinking waters) would reduce the number of new caries lesions, but there was more: a prominent ORCA member, Dr. Gutherz, a school dentist in Basel, had a graph composed which he used widely in the early 1960s when he was fighting for the introduction of water fluoridation in his Kanton. It showed that not only was the number of lesions halved by fluoride, but that lesions were much smaller. This would permit minimally invasive cavity preparation, as opposed to the more difficult, if not impossible, larger cavity preparations needed in the absence of fluoride.

In Zürich the school dentists applied - as a treatment principle - the extraction of all four first permanent molars soon after their eruption; this was done for three reasons:

(1) The molars became carious with rapid progression which had already begun during eruption, so that when the child saw the dentist it was often too late for successful treatment.

(2) Usually, due to premature loss of deciduous molars, before the age of 6 the space for the erupting premolars and canines had already been lost.

(3) Rather than keep the ruins of four heavily filled teeth in a child's mouth, the first molars were extracted early giving the second and third molars a much better chance to survive in proper function.

It was questionable whether these arguments were valid but, that apart, the very fact that systematic extraction of all first molars was practiced on a large scale as a treatment strategy in Switzerland illustrates how serious the caries problem was in the 1950s and 60s. So extreme an approach to treatment of caries and its sequelae would otherwise never have been considered.

In the Netherlands (Nijmegen) in 1969 during the baseline examination of approximately 1,000 children aged 7 years, it was very obvious that all the dental practitioners had adopted the principle not to fill any deciduous teeth and the amalgam fillings in the permanent molars were unpolished [Plasschaert and König, 1973]. The explanation was that The Netherlands (like Belgium) had the lowest dentist:population ratio in Europe, 1:4,000, and the need and unmet demand for dental treatment was tremendous. As a matter of fact, in the Nijmegen sample of nearly 1,000 children only 3 were found to be cariesfree. This may not have been representative, but a health education slide series issued by the 'Ivory Cross', also in 1969, described a situation which was not very much better than the one in Nijmegen [Van zoet naar zuur, 1969]. Especially sad was the fact that exodontism rather than repair resulted in too many young adults being edentulous. 


\section{Water Fluoridation Effects versus Caries Decline in Non-Fluoridated Areas}

In the Netherlands public health dentists under the leadership of ORCA Honorary Member Otto Backer Dirks had been fighting for water fluoridation since 1953.

In 1953 fluoridation of drinking water was started in the city of Tiel on an experimental basis; in 1970 the gradual increase in the number of fluoridated areas resulted in nearly half the population of the Netherlands receiving fluoridated water. However, due to the untiring efforts of antifluoridationists, fluoridation stopped in the whole country after a supreme court decision in 1973 [Kalsbeek and Verrips, 1990]. This generated great concern amongst the dental professionals because everybody was afraid that the deplorable situation of dental ill health experienced in the 1950s and 60s would recur. But this miraculously did not happen; on the contrary, the changes in the average DMFT of 12-year-old children over the whole country show that the decrease of caries prevalence had only just started when water fluoridation ceased in 1973; the average DMFT of 8 at that time in 12-year-old children consistently decreased to a DMFT of 1 by the mid 1990s [Truin et al., 1994, 1998; Marthaler, 2003].

The most plausible reason for this success is that dental health educators and enlightened mothers and fathers were alarmed when they realized that after water fluoridation stopped good dental health could no longer be obtained out of their water taps but needed their individual effort. It was therefore obvious that everybody had to become active and apply preventive measures on an individual basis. The results of this in the Netherlands were quite unexpected. Although health educators had persistently and clearly said 'eat less sugar', this did not happen. Sugar consumption did not decrease substantially: being $38.5 \mathrm{~kg}$ per person per year in 1985 , and the same quantity in 1992, it was still more than $90 \%$ of what it had been in 1965. Therefore the improvement in dental health could not be attributed to improvement in our eating habits. It also could not be attributed to administration of fluoride supplements, because the sales of fluoride tablets had always been low and were decreasing continuously. Topical application of fluoride gels and growing popularity of sugarless chewing gum may have contributed, but the most important reason for the improvement was a rapid spread of good oral hygiene habits and the use of fluoride toothpastes. What certainly played a role in this success story was the fact that from the early 1950s preventive dentistry was embraced by dental professionals, the community health authorities, and academic dentistry. By 1969 all five dental schools in the Netherlands had a chair in this discipline. Moreover, individual communities had started large-scale health education campaigns, covering not only the importance of healthy nutrition, but also stressing the great importance of oral hygiene. At the same time, hygiene in general became socially desirable.

Since the mid-1980s most children have had very little or no plaque and are using a fluoride-containing toothpaste. The analysis of the Delphi investigation into the reasons for the decline in caries by Bratthall et al. [1996] showed that an overwhelming majority, $96 \%$ of the 55 experts, thought that the use of fluoride toothpastes was 'very important' or 'important'. Regarding sugar consumption, $87 \%$ of the experts thought this was of little or no importance.

\section{Sugar Intake as a Caries Risk Factor}

Sreebny in 1982 had published an analysis of the sugarcaries relationship. He had based the analysis on the caries data in deciduous dentitions from 23 countries and on data in permanent dentitions from 47 countries. He found that every 20-gram increase in the sugar consumed more per person per day (or $7.3 \mathrm{~kg}$ per year) resulted in 0.5 $\mathrm{dmft}$ increase in 5- to 6-year-old children, and 1 DMFT increase in 12-year-olds. Soon after it had been published this observation was proved not to be valid.

There were some countries where between 1982 and 1985 the sugar consumption had increased, but where, nevertheless, regular epidemiological monitoring of caries data had shown that the caries prevalence in children continued to decrease: these were Sweden [Birkhed et al., 1989], Norway [Rølla and Øgaard, 1987], and New Zealand [König, 1990].

Shortly after the publication by Walker and CleatonJones [1989], Marthaler [1990] published his analysis of the secular trends in caries prevalence and came to the confirmatory conclusion that in many highly developed industrialized countries there was a 'lack of correlation between the decline of caries prevalence and average sugar consumption'.

This is a comforting statement. However, there are still high-risk populations who demand our attention. These are found in developing countries, or in subpopulations (mostly ethnic minority groups) in the highly developed 'low-caries countries', such as the refugees from former Yugoslavia in Switzerland [Menghini et al., 2003]. These at-risk subpopulations should be the target of appropriate, 
effective prevention and treatment strategies. A specific analysis of risk factor(s) per risk group is necessary, and a specific package of preventive measures should be composed to limit the manifestations of caries and reduce treatment need.

\section{Root Caries and the Secular Change of Caries Prevalence in the 1980s}

The urgent problems caused by the high incidence and rapid progression of caries in young people made us neglect a typical problem inflicting the elderly with gingival recession, root caries. In the 3 decades between 1954 and 1983 only 14 studies on root caries were carried out [Wagg, 1984]. One of them was the first representative population study on root caries by the Finnish group of Vehkalati et al. [1983], the results of which they started to publish in 1983. It showed that the prevalence was less in women than in men (1.19 vs. $2.23 \%$ of teeth affected). At that time the authors already assumed that the prevalence of root caries differed widely in populations of different ethnic, cultural and socio-economic background. Whether this manifestation of caries fully deserves the increased attention it received in the late 1980 s, or whether the problem of root caries has, in the meantime, been replaced by the problem of toothbrush abrasion of the exposed roots will depend on one's perspective. However, root caries is another interesting example on how the manifestations of caries and its treatment can be drastically modified by preventive measures; Nyvad and Fejerskov [1986] persuaded patients with root caries to practice meticulous toothbrushing with a toothpaste containing 1,000 ppm F. Within 2-6 months the lesions changed from a clinically active stage into inactive stages of caries. Subsequently, this success which tended to make traditional drilling and filling superfluous, has been repeated using various modes of fluoride applications [Lynch and Baysan, 2001].

\section{Caries Manifestations, Treatment, Overtreatment and Undertreatment}

Some manifestations of caries which accompanied the generally improved dental health in highly developed countries are very characteristic: smooth surface caries has become very rare; approximal caries declined drastically, and fissures were sealed or treated by minimally invasive methods without extension for prevention. More time became available for the aesthetic aspects of treatment, tooth-coloured adhesive materials being applied in anterior and even in posterior teeth.

Some older and somewhat reactionary dentists adhered mentally to the previous desolate scene of rampant caries, and rapid progression of small caries lesions. They tended to overestimate the caries risk and did not trust modern recommendations to wait and give remineralization a chance. They practiced overtreatment, excavating and filling small lesions instead of sealing fissures or applying remineralizing agents to sites of incipient attack.

The reference in the title to 'global changes' should not be taken literally. The situation worldwide was and remains today extremely variable and changes are occurring in different directions. In industrialized countries, there has been great improvement, but in some developing countries deterioration has been observed. There are other instances where the manifestations of caries are pretty stable. However, some countries, in particular on the African Continent, are developing very slowly and due to lack of financial resources cannot provide modern dental services; in these cases the method of atraumatic restorative treatment (ART) is an adequate alternative [Frencken and Holmgren, 1999; Massara et al., 2002]. The filling materials are modern glass-ionomers, and the preparation is minimally invasive, but the preceding excavation is carried out with hand instruments, and so - again - we return to G.V. Black.

It is obvious that this atavistic treatment method was born out of the necessity to help patients in poor developing countries, while progress with new, advanced techniques is available in the highly industrialized rich countries. The conclusion therefore must be that the highest priority should not be the development of even more advanced treatment techniques, but the global fight against poverty which threatens the health of large parts of the world population. 


\section{References}

Birkhed D, Sundin B, Westin SI: Per capita consumption of sugar-containing products and dental caries in Sweden from 1960 to 1985. Community Dent Oral Epidemiol 1989;17:4143.

Black GV: Susceptibility and immunity to dental caries. Dental Cosmos 1899;41:826-836.

Black GV: Konservierende Zahnheilkunde. Berlin, Meuser, 1914, vol 2: Die Technik des Zahnfüllens.

Bratthall D, Hänsel-Petersson G, Sundberg H: Reasons for the caries decline: What do the experts believe? Eur J Oral Sci 1996;104:416-422.

Dean HT, Arnold FA, Elvove E: Domestic water and dental caries. V. Additional studies of the relation of fluoride domestic waters to dental caries experience in 4,425 white children aged 12-14 years of 13 cities in 4 states. Public Health Rep 1942;57:1155-1179.

Frencken J, Holmgren CJ: Atraumatic Restaurative Treatment. Nijmegen, STI Book bv, 1999.

Hofheinz RH: Extension for prevention. Dental Cosmos 1902;44:914-919.

Kalsbeek H, Verrips GHW: Dental caries prevalence and the use of fluorides in different European countries. J Dent Res1990;69(special issue):728-732.

König KG: Changes in the prevalence of dental caries: How much can be attributed to changes in diet? Caries Res 1990;24(suppl 1):16-18.

Lynch E, Baysan A: Reversal of primary root caries using a dentifrice with a high fluoride content. Caries Res 2001;35(suppl 1):60-64.
Marthaler TM: Changes in the prevalence of dental caries: How much can be attributed to changes in diet? Caries Res 1990;24(suppl 1):3-15.

Marthaler TM: Dentistry between pathology and cosmetics. Community Dent Oral Epidemiol 2002;30:3-15

Marthaler TM: Dental caries - past and present: Changes in dental caries 1953-2003. Caries Res 2004;38:173-181.

Massara MLA, Alves JB, Brandão PRG: Atraumatic restorative treatment: Clinical, ultrastructural and chemical analysis. Caries Res 2002;36: 430-436.

Menghini G, Steiner M, Marthaler TM, Helfenstein U, Brodowski D, Imfeld C, Weber R, Imfeld T: Kariesprävalenz von Schülern in 16 Zürcher Landgemeinden in den Jahren 1992 bis 2000. Schweiz Monatsschr Zahnmed 2003; 113:267-277.

Nyvad B, Fejerskov Ø: Active root surface caries converted into inactive caries as a response to oral hygiene. Scand J Dent Res 1986;94:281284.

Plasschaert AJM, König KG: Die Wirkung von Zahngesundheitsinformatiion und von Fluoridtabletten auf den Karieszuwachs bei Schulkindern. Schweiz Monatsschr Zahnheilkd 1973;83;421-445.

Rølla G, Øgaard B: Reduction in caries incidence in Norway from 1970 to 1984 and some considerations concerning the reasons for this phenomenon; in Frank RM, O'Hickey S (eds): Strategy for Dental Caries Prevention in European Countries According to Their Laws and Regulations. Oxford, Information Retrieval, 1987, pp 223-229.
Sreebny LM: Sugar and human dental caries. World Rev Nutr Diet 1982;40:19-65.

Todd JE, Whitworth A: Adult Dental Health in Scotland 1972. London, Office of Population Censuses and Surveys, Social Survey Division, HMSO, 1974.

Truin GJ, König KG, Bronkhorst EM, Frankenmolen F, Mulder J, van't Hof MA: Time trends in caries experience of 6- and 12-year-old children of different socioeconomic status in The Hague. Caries Res 1998;32:1-4.

Truin GJ, König KG, Bronkhorst EM, Mulder J: Caries prevalence amongst schoolchildren in The Hague between 1969 and 1993. Caries Res 1994;28:176-180.

Van zoet naar zuur (From Sweet to Acid): Dental Health Education slide series. Rotterdam, Het Ivoren Kruis, 1969.

Vehkalahti M, Rajala M, Tuominen R, Paunio I: Prevalence of root caries in the adult Finnish population. Community Dent Oral Epidemiol 1983;11:188-190.

Wagg BJ: Root surface caries: A review. Community Dent Health 1984;1:11-20.

Walker ARP, Cleaton-Jones PE: Sugar intake and dental caries: Where do we stand? J Dent Child 1989;56:30-35. 